\title{
THE PATHOGENESIS OF INFARCTION OF THE RIGHT VENTRICLE
}

\author{
BY \\ W. G. WADE \\ From The Institute of Pathology, Queen's University, Belfast
}

Received February 4, 1959

In myocardial infarction it is rare for the right ventricle to be predominantly affected. The relative incidence of infarction of this ventricle in two large series has been shown to be 1.7 per cent (Bean, 1938) and 3 per cent (Wartman, 1948) respectively. In the average human heart the entire right ventricle with the exception of the left third of the anterior wall is supplied by the right coronary artery (Gross, 1921). However, the uncommon occurrence of right ventricular infarction bears no relationship to the frequency with which this artery is occluded. Schlesinger and Zohl (1941) showed from their perfusion studies of human hearts at necropsy that the right coronary artery was occluded in 34 per cent of all main stem occlusions. In comparison, the corresponding figures for the anterior descending and circumflex branches of the left coronary artery were 39 per cent and 27 per cent respectively.

Blumgart et al. (1940) have suggested that the right ventricular Thebesian system accounts for the immunity of this ventricle to infarction. Wood (1956) on the other hand, has asserted that it is protected through being supplied by the two biggest coronary arteries and because it offers less resistance to systolic coronary flow than the left ventricle.

In this communication, the pathological and clinical features of eleven new cases of right ventricular infarction are presented; this constitutes the largest series of cases of this kind that has so far been published. In addition, nine examples previously reported are reviewed and the main aetiological factors that emerge are discussed in relation to the results of recently reported physiological experiments.

The clinical data and the gross pathological findings in the eleven new cases were obtained from the records in this Institute. The histological material was available from each case and was personally reviewed using the criteria laid down by Mallory (1939) for estimating the age of an infarct. For comparison, the corresponding gross pathological features in a consecutive series of 100 cases of left ventricular infarction investigated in this Institute were also assembled.

\section{Gross Pathological Features of Right Ventricular Infarction}

Of the eleven cases here described only one was a woman. A similar sex distribution is found in those cases previously described in which two out of the eight cases where the sex was given were woman [Sanders, 1930; Sprague and Orgain, 1935, two cases; Feil et al., 1938; Weinberg and Katz, 1941; Roberts and Loube, 1947; Case 34442 (M.G.H.) 1948, and Zaus and Kearns, 1952]. In this series (Table I) the mean age for the eleven cases was 65.5 years, but the range was wide, being 40-84 years.

In ten hearts in which the relative thickness of the ventricular wall was described, left ventricular hypertrophy was present in six and in four of these there was also right ventricular hypertrophy.

The right coronary artery was occluded by a recent thrombus in nine hearts and by an old organized lesion in one other. In those hearts with recent occlusions of the right coronary artery there were five in which additional old occlusions were found; of the left anterior descending coronary artery in four and of the left circumflex artery in the fifth. One heart in this series 
without an occlusion of the right coronary artery had a recent occlusion of the left anterior descending coronary artery (Case 8), In most of those vessels without occlusions moderate to severe degrees of atheroma were present. Of eight previously published cases, including one reported by McDonald and Bentley (1951), the pattern of the coronary arterial lesions was identical with that described above. In each case the right coronary artery was occluded by a recent thrombus and in one instance there was an associated old occlusion of the left anterior descending coronary artery. In the case cited by Weinberg and Katz the arterial lesions were not described. Hence out of a total of nineteen hearts with right ventricular infarction the right coronary artery was occluded in eighteen.

As shown in Table I the anterior wall of the right ventricle was involved in an infarct in only three hearts and then always in a focal manner, the major lesion with one exception being in the

TABLE I

Pathological Findings in Right Ventricular Infarction

\begin{tabular}{|c|c|c|c|c|c|c|}
\hline \multirow{3}{*}{ Case } & \multirow{3}{*}{$\begin{array}{l}\text { Sex } \\
\text { and } \\
\text { age }\end{array}$} & \multicolumn{5}{|c|}{ Myocardial infarction } \\
\hline & & \multicolumn{3}{|c|}{ Recent } & \multicolumn{2}{|c|}{ Old } \\
\hline & & Right ventricle & $\begin{array}{l}\text { Posterior septum } \\
\text { and left ventricle }\end{array}$ & $\begin{array}{l}\text { Right } \\
\text { atrium }\end{array}$ & Right ventricle & Left ventricle \\
\hline 1 & M40 & $\begin{array}{l}\text { Posterior transmural } \\
\text { ruptured }\end{array}$ & Ext. & $?$ & - & - \\
\hline 2 & M67 & Posterior transmural & - & Ext. & - & Anterior \\
\hline 3 & M69 & $\begin{array}{l}\text { Postero-lateral } \\
\text { transmural }\end{array}$ & Ext. & Ext. & - & Anterior \\
\hline 4 & M48 & $\begin{array}{l}\text { Posterior (healing) } \\
\text { transmural }\end{array}$ & - & - & - & Diffuse fibrosis \\
\hline 5 & M84 & - & - & - & Anterior focal & Anterior focal \\
\hline 6 & F79 & $\begin{array}{l}\text { Posterior (healing) } \\
\text { transmural }\end{array}$ & - & Ext. & $\longrightarrow$ & 一 \\
\hline 7 & M70 & - & - & - & Anterior focal & Anterior focal \\
\hline 8 & M64 & $\begin{array}{c}\text { Anterior focal } \\
\text { transmural }\end{array}$ & - & - & - & - \\
\hline 9 & M62 & Posterior transmural & Ext. & - & - & Anterior \\
\hline 10 & M70 & 一 & Ext. & - & - & - \\
\hline 11 & M68 & Posterior transmural & Ext. & - & - & - \\
\hline
\end{tabular}

Ext. Direct extension of infarct.

posterior wall of the right ventricle. Similarly, anterior lesions of the right ventricle have been reported only twice (Sprague and Orgain, and Feil et al.), and these were also focal. In all of the published cases the predominant lesion was present in the posterior wall of the right ventricle. This posterior location is, therefore, an important feature of infarction of this ventricle and is undoubtedly related to the anatomical course of the right coronary artery.

Extension of the infarct to the adjacent part of the posterior interventricular septum and to the adjoining portion of the posterior wall of the left ventricle was present in four cases in this series (Table I). Sanders, Sprague and Orgain, and Zaus and Kearns described similar extensions of the 
lesions in their cases. These extensions of the infarct were almost certainly a result of occlusion of a right coronary artery that in its distribution dominated the posterior wall of the heart. In addition, the right atrium was involved in three cases in this series and in those reported by Feil et al., Roberts and Loube, and Zaus and Kearns. The overall incidence of involvement of the right atrium in right ventricular infarction is, therefore, about 35 per cent. This is appreciably greater than the figure of 14 per cent obtained by Cushing et al. (1942) in a general series of 182 cases of myocardial infarction in which the right atrium was specifically examined for this lesion. The greater incidence of right atrial involvement is explained by the fact that the right coronary artery is usually the most important source of blood to the atria (Gross, 1921).

The extensive lesions that involved the right ventricle were almost invariably of recent origin whereas the old lesions were usually focal. It would appear, therefore, that a widespread lesion of the posterior cardiac wall that mainly involves the right ventricle carries a poor prognosis. Another striking feature in the present series is the high proportion of transmural lesions among right ventricular infarcts. It is probably the relatively thin wall of the right ventricle that predisposes it to this type of lesion.

Yet a further point of interest is the location of those infarcts and arterial occlusions that were found, in addition to the lesions present in the right ventricle and right coronary artery. In about half the cases now presented (Table I) and previously reported these additional older lesions were present in the distribution of the left anterior descending artery. Since the arterial pattern on the posterior wall of the human heart is usually dominated by the right coronary artery, it follows that when this vessel is occluded the right ventricle will obtain much of its inter-coronary collateral blood-supply from those branches of the left coronary artery that already ramify in the interventricular septum and anterior third of the right ventricle. These branches are derived from the anterior descending artery. Hence occlusion of this latter vessel greatly diminishes the chances of survival of the right ventricular myocardium when a dominant right coronary artery becomes occluded. In nine of the hearts in this series in which the arterial pattern on the posterior wall was described, a dominant right coronary pattern was present in each case.

In five of the patients in the present series there was evidence of an hepatic lesion, i.e. central zonal necrosis, chronic venous congestion or cardiac cirrhosis, developing secondarily to congestive heart failure. As will be seen later, this complication can give rise to difficulties in clinical management.

A numerical comparison of some of the gross pathological findings in right and left ventricular infarction reveals several rather interesting contrasting features. The infrequent occurrence of right ventricular infarction has made it necessary to include previously published case reports in order to give added weight to the figures in this group.

The mean age in cases of right ventricular infarction (Group A) is 62 years, whereas in left ventricular infarction (Group B) it is 69 years. This lower mean age may account for the smaller proportion of women in the former group $(18 \%)$ compared with the latter $(34 \%)$. The mean weights of the male hearts in Groups A and B were 531 grams and 502 grams respectively. There is, therefore, no significant difference for the two groups, but it is notable that left ventricular hypertrophy and cardiac enlargement are frequently associated with right ventricular infarction.

The incidence of the subsequent features of the two groups is shown in Table II. Right ventricular hypertrophy is found one and a half times as frequently in Group A as it is in Group B, and this coupled with a fourfold increase in the incidence of chronic pulmonary lesions in Group A suggests a relationship between pulmonary hypertension and right ventricular infarction. This relationship has probably a similar significance to that of systemic hypertension in left ventricular infarction (Palmer, 1937). It is unlikely that isolated case reports of healed right ventricular infarction have ever been considered worth publishing, and to avoid a bias in these figures those cases quoted from earlier records have been omitted. While there is no significant difference in the incidence of recent infarction, multiple infarction, and arterial occlusions in the two groups, there 
TABLE II

Comparison of the Main Features of Right and Left Ventricular Infarction

\begin{tabular}{|c|c|c|c|c|c|c|}
\hline & & & \multirow{2}{*}{$\begin{array}{c}\begin{array}{c}\text { Calculated incidence } \\
\text { in } 100 \text { cases of } \\
\text { right ventricular } \\
\text { infarction }\end{array} \\
\text { Group A }\end{array}$} & \multirow{2}{*}{$\begin{array}{c}\begin{array}{c}\text { Incidence } \\
\text { in } 100 \text { cases of } \\
\text { left ventricular } \\
\text { infarction }\end{array} \\
\text { Group B }\end{array}$} & \multicolumn{2}{|c|}{$\begin{array}{l}\text { Actual } \\
\text { number of } \\
\text { cases }\end{array}$} \\
\hline & & & & & Group A & Group B \\
\hline Coronary artery occlusions & .. & .. & 150 & 124 & 19 & 100 \\
\hline Multiple infarction & . & . & 55 & 32 & 20 & 100 \\
\hline Recent infarction & . & . & 64 & 55 & 11 & 100 \\
\hline Ruptured recent infarcts* & .. & . & 12 & 12 & 17 & 58 \\
\hline P'ericarditis & . & . & 50 & 15 & 16 & 100 \\
\hline Right-sided mural thrombi $\dagger$ & .. & . & 125 & 4 & 16 & 100 \\
\hline 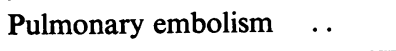 & .. & .. & $73 \ddagger$ & 8 & 11 & 100 \\
\hline Left-sided mural thrombi & .. & .. & 27 & 22 & 16 & 100 \\
\hline Systemic embolism & .. & .. & 23 & 8 & 13 & 100 \\
\hline Right ventricular hypertrophy & .. & .. & 58 & 38 & 12 & 100 \\
\hline Chronic pulmonary lesions $\S$ & .. & .. & 36 & 9 & 14 & 100 \\
\hline
\end{tabular}

* Calculated incidence per 100 cases of recent ventricular infarction.

$\dagger$ Thrombi present in right atrium and right ventricle.

‡ Extra-cardiac source of pulmonary emboli found in 3 cases.

$\S$ Diffuse emphysema, chronic bronchitis, pulmonary fibrosis.

appears to be a greater tendency for right ventricular infarction to develop in hearts that have already been the seat of extensive ischæmic disease.

Pericarditis occurred four times as frequently in Group A as it did in Group B-cases and this is probably a consequence of the greater liability of the right ventricle to develop a transmural lesion.

Although right ventricular cavity pressures are normally only about a sixth of those that obtain within the left ventricle, rupture through a recent infarct appears to occur as readily through the right ventricular wall as it does through the left. In the aetiology of rupture through a myocardial infarct the importance of the role of the transmural lesion has been stressed by Wartman and Souders (1950). According to Gould (1953) adiposity of the myocardium may also be a factor in precipitating rupture through an infarct: in the older age groups the right ventricular wall is very prone to develop adipose changes and in many of the Group A series of hearts which were examined in this Institute such changes were found. The incidence of mural thrombi developing in the right side of the heart in Group A was thirty times greater than it was in Group B whereas the frequency with which left-sided mural thrombi developed was equal for each group. The much greater tendency for right-sided mural thrombi to develop in the Group A series was probably largely dictated by the transmural type of lesion that generally developed in the right ventricular wall. However, the greater number of ischæmic lesions and the lower pressures that prevailed in the affected chambers on the right side of the heart were possibly contributory factors also. Unfortunately it is impossible to estimate precisely how far the figures for mural thrombosis were influenced by the use of anticoagulants; however, the cases in both groups embrace the periods before and after this form of therapy came into general use.

It is clear that the higher incidence of pulmonary embolism in Group A which is nine times 
greater than it is in Group B is directly related to the much greater tendency for right-sided mural thrombi to develop in right ventricular infarction. Admittedly, however, the incidence of pulmonary embolism is necessarily influenced by the incidence of systemic venous thrombosis which is not always easily detected at necropsy. This incidence is probably higher in right ventricular infarction owing to the frequency of congestive failure, which is evident from the number of secondary hepatic lesions found in these cases.

\section{HISTOLOGY}

In all those infarcts that were investigated in this Institute, the overall pattern was almost identical with that seen in left ventricular infarction. Even the thin zone of subendocardial myocardium underlying the area of infarction was often preserved, thus indicating that there was no blockage of the Thebesian channels in the right ventricle. It was noteworthy that this preserved zone represented about one-sixth of the total thickness of the right ventricular cavity. Neither does the prevalence of adiposity of the right ventricular myocardium allow for the possibility that vessels in adipose tissue can effectively protect the right ventricle from infarction.

The degree of atheroma and thrombo-occlusive disease of the coronary arteries in these hearts was quite sufficient to account for the unusual location of these infarcts, and arteritis was excluded as being a possible ætiological factor.

\section{Clinical Features}

The clinical features of only seven of the eleven cases from this Institute are considered here. In the other four (Cases 3, 5, 7, and 8) the presence of an infarct was apparently overlooked altogether and consequently the clinical records are not helpful.

A note of the systemic blood pressure taken before the onset of the right ventricular infarct was available in three instances (Cases 3, 9, and 10) and in each hypertension was present. This conforms to the frequent finding of left ventricular hypertrophy in this series.

An enquiry was made into a history of dyspnœa preceding the final illness in four cases and a positive history was obtained in three (Cases 2, 3, and 10). In two of these (Cases 3 and 10) there was a chronic pulmonary lesion in addition to the old coronary arterial occlusions found at necropsy. Five of the seven patients experienced præcordial pain at the onset of their final illness but in two elderly patients (Cases 3 and 6) who had no pain, atrial fibrillation was present. The association of this arrhythmia with the absence of præcordial pain is not easily explained, but it is a clinical phenomenon that has been recognized by Evans (1956).

Clinical evidence of circulatory failure was present in all seven patients and in five of the six in which reference was made to right-sided heart failure (Cases 2, 3, 6, and 10) this also supervened.

The average duration of survival from the onset of the right ventricular infarct for the seven cases was three weeks, with a range of seven to fifty-four days. The tendency for right ventricular infarction to develop in hypertrophied hearts that are already the seat of ischæmic disease, and the fact that embolic phenomena are prone to develop, may partly explain the relatively grave prognosis associated with these cases.

\section{CASE REPORT}

The following report of Case 3 illustrates most of the pathological and clinical features of right ventricular infarction already recorded.

A 70-year-old man collapsed on the street on September 15, 1951, and was admitted to hospital. During the previous three years he had been admitted on several occasions with a diagnosis of hypertensive heart disease (blood pressure 200/120) and atrial fibrillation. Right-sided heart failure had supervened on one occasion.

On the day of his final admission, examination showed a kyphotic man with moderate cyanosis, cold extremities, and atrial fibrillation. The blood pressure was 70/40. There was evidence of right-sided heart 
failure and an electrocardiogram showed a recent posterior infarct (Fig. 1). Records taken during earlier admissions showed ischæmic changes over the anterior wall of the left ventricle (Fig. 2). Despite recovery from circulatory failure, the clinical features of right-sided heart failure persisted, and a downhill course ensued. The picture was complicated by bronchitis and urinary obstruction, and the patient died in coma following a convulsive seizure four weeks after admission.

During his first illness, the patient's prothrombin time (Quick's one-stage method) was less than 20 per cent on three separate occasions and anticoagulant therapy was, therefore, never instituted.



Fig. 1.-Case 3. Electrocardiogram of a man, aged 70, showing atrial fibrillation and recent posterior infarction of the heart. Necropsy showed thrombotic occlusion of the right coronary artery and a recent infarct of the right ventricle (see text).

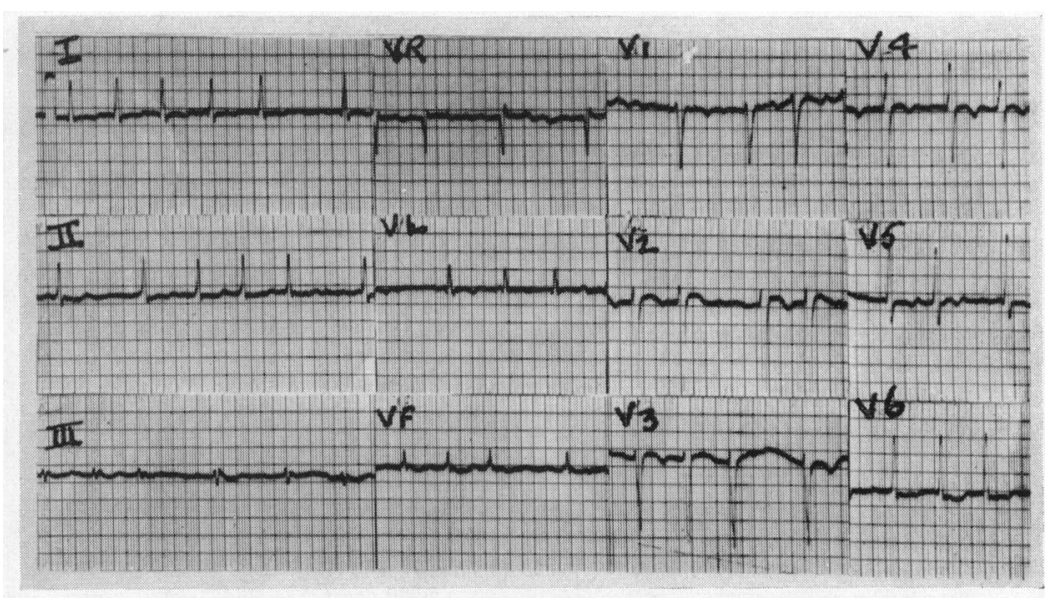

FIG. 2.-Case 3. Electocardiogram during earlier admission to hospital, showing fast atrial fibrillation and ischæmic heart disease involving the left ventricle antero-laterally.

Summary of Findings at Necropsy. Atheroma of aorta and cerebral and coronary arteries; recanalized occlusion in the left anterior descending coronary artery; healed infarct in the left ventricle with recent and organized endocardial thrombus. There was an old infarct of the spleen, with chronic venous congestion of the liver and pancreas and cardiac cirrhosis. There was an organizing thrombotic occlusion of the right coronary artery, and recent infarct of the right ventricle, involving the posterior part of the septum, part of posterior wall of the left ventricle and the right auricular appendage, with diffuse pericarditis: organizing 
endocardial thrombus was seen in the right ventricle and right auricular appendage; there were also organizing and organized pulmonary emboli with pulmonary infarcts. Kyphosis was present with emphysema of the lungs, and right ventricular hypertrophy. Hæmorrhagic cystitis and acute pyelo-nephritis which may have followed catheterization were observed.

Comment. Egeli (1956), using liver function tests in conjunction with liver biopsy studies, found evidence of severe hepatic dysfunction in seventeen out of thirty-one cases of liver disease occurring secondarily to congestive heart failure. Impaired liver function was found in the case recorded by Zaus and Kearns and in Case 3 cited above, and it is highly probable that the prolonged prothrombin times resulted from cardiac cirrhosis and chronic venous congestion. The danger of embolism developing in these cases is so great that it is imperative to use a coumarin preparation; nevertheless, it is clear that great care must be exercised in the presence of hepatic insufficiency which is so liable to arise in right ventricular infarction.

\section{The EleCtrocardiographic Diagnosis of Right Ventricular Infarction}

Electrocardiograms were obtained in only three of the series (Cases 3, 8, and 9) here presented. Case 8 which was associated with a small anterior infarct in the right ventricle merely showed T-wave inversion in leads I and V4-6. The classical cardiographic features of posterior infarction were shown in Cases 3 and 9 in which there was extensive infarction of the posterior cardiac wall. The gross involvement of the right ventricle was not apparent from the præcordial leads in either of these two electrocardiograms.

In eight of the, nine previously reported cases, the electrocardiographic findings are recorded, although unipolar leads were obtained in only three instances. In six of these electrocardiograms there was clear evidence of the presence of a posterior infarct and in the other two there was inversion of the $\mathrm{T}$ waves in leads II and III. Of the three cases with unipolar præcordial leads evidence of right ventricular involvement was apparent in only one instance (Levy and Hyman, 1950): it showed elevation of the S-T segments and a prominent QS complex in leads V1-3, an RS complex and isoelectric S-T segment in lead V4, as well as Rs complexes and depressed S-T segments in leads V5-6.

A striking feature in four of the previously reported cases was the presence of atrio-ventricular dissociation. According to White (1947), this type of arrhythmia may arise when there is an acute occlusion of the right coronary artery or of the left circumflex vessel, since the major part of the blood supply to the atrio-ventricular junctional tissue is nearly always derived from these vessels.

With the exception of the case of Levy and Hyman it would appear that even with the use of præcordial leads the chance of arriving at a diagnosis of right ventricular infarction is very remote. The over-riding difficulty in making this diagnosis lies in the fact that electrical impulses arising in the smaller mass of the right ventricle are inundated by those arising in the left ventricle. Nevertheless, a diagnosis of posterior infarction can often be achieved in these cases; the right ventricular infarct being posterior in its distribution. Unless the right ventricular infarct is sufficiently extensive to involve the antero-lateral wall of the right ventricle and thus confront the right præcordial leads, it is impossible to localize the infarct to this ventricle. In order that more than one right præcordial lead is confronted by the infarct the heart will require to lie in a vertical electrical position and be rotated in a clockwise direction in its longitudinal axis. However, this position is frequently compromised in these cases by the presence of left ventricular hypertrophy. To surmount this difficulty Levy and Hyman (1950) have suggested taking accessory præcordial leads superior to leads V2 and V3.

The early stages of an extensive right ventricular infarct will result in elevation of the RS-T segment in leads overlying the infarct and reciprocal depression of the RS-T segment in the left præcordial leads (Johnston, 1956). A recent subendocardial infarct situated in the postero-lateral wall of the left ventricle can also produce these changes. Moreover, in the later stages of a right ventricular infarct, the expected abnormal $Q$ waves and diminished $R$ waves will be obscured by 
electrical impulses arising from the right side of the interventricular septum, since this also confronts the right præcordial leads.

The frequent association of right and left ventricular hypertrophy, pericarditis, pulmonary embolism, and the use of digitalis therapy in right-sided heart failure will also complicate the electrocardiogram since they are all capable of producing $\mathrm{S}-\mathrm{T}$ segment and $\mathrm{T}$ wave changes in the right præcordial leads.

A diagnosis of right ventricular infarction can, therefore, only be made under exceptional circumstances. Provided that a diagnosis of myocardial infarction is made at all greater precision is not important, for in most instances the gravity of the condition will indicate the use of anticoagulants anyway.

\section{Discussion}

The view of Blumgart (1940) that the immunity of the right ventricle to infarction is a result of its superior collateral Thebesian system was based largely on the experimental work of Wearn (1928 and 1933). This work, which involved the preparation of casts of the ventricular chambers disclosed a more elaborate Thebesian system on the right side. However, Blumgart's view is untenable for several reasons.

A more recent experiment with which Wearn was associated (Eckstein et al., 1941) has demonstrated that in dogs the right ventricular vasculature can only be filled from the right ventricular chamber when the pressures in that chamber exceed those in the left. Such a relationship could only arise in a congenital heart lesion. In Wearn's original experiments, the pressures used for preparing casts of the right ventricular chamber were unphysiological.

Cinematographic studies (Prinzmetal et al., 1948) in dogs have established that blood flowing into an ischæmic area of right ventricle is, in fact, arterial in origin. In conjunction with the pathological evidence already presented, these findings appear to rule out any likelihood that the right ventricular Thebesian system can protect the right ventricle from infarction. The existence of vascular connexions between the coronary arteries and branches of the internal mammary, anterior mediastinal, bronchial, phrenic, intercostal, and œsophageal arteries has long been established, but the high incidence of transmural lesions and pericarditis in right ventricular infarction suggests that these anastomoses are of little importance to the right ventricle.

The frequent association of sclerosis of either the left anterior descending coronary artery or of the left circumflex branch with right ventricular infarction indicates the importance to the right ventricle of the inter-coronary collateral circulation. In prolonged experiments in dogs it has been shown that when a coronary artery is ligated, its collateral supply is largely derived from the other main coronary arteries (Gregg, 1950). Nevertheless, right ventricular infarction has been readily produced in animals by ligation of the right coronary artery only. These were, however, acute experiments and may simulate more closely those few human cases of right ventricular infarction where the only arterial lesion was a recent thrombus in the right coronary artery (Table I, Case 4, and Sanders, 1930).

In the majority of human hearts with atheroma of the coronary arteries, the time allowed for inter-coronary collateral channels to open up and enlarge as a result of stenosis developing in one of the major vessels is evidently sufficient to provide for an adequate alternative circulation to the right ventricle. On the other hand, the metabolic requirements of the left ventricle are much greater, not only because of its greater mass, but also because, under normal conditions, it probably performs about three times as much work, weight for weight, as the right ventricle (Gregg, 1950). These additional requirements can be met either by a collateral circuit of greater magnitude or by an increase in the rate of inter-coronary collateral flow. In the absence of any appreciable muscle coat the collateral channels are incapable of undergoing vasodilatation and thus cannot facilitate rapid local changes in the rate of flow (Wade, 1957).

In addition, there are certain other factors that operate in favour of the right ventricle. First, according to quantitative perfusion experiments carried out in human hearts (Prinzmetal et al., 1942) 
the collateral flow to the left coronary arterial system is only about one-third of that available in the opposite direction. Secondly, it has been disclosed from experiments on dogs that the systolic coronary inflow is relatively greater for the right artery than for the left (Gregg). Since ischæmic myocardium can offer only passive resistance to the intra-ventricular cavity pressures, the collateral flow during systole will meet with much more resistance when flowing from the right to the left arterial system than when the reverse is the case. Finally, Wiggers (1954) has shown the important influence on coronary flow of the compressor effect of contracting myocardium on intramural vessels. Under similar conditions the flow across the inter-coronary collateral vessels during systole will clearly be more strongly augmented by the compressor effect of the left ventricular myocardium than by that of the right.

The development of circulatory failure in patients with right ventricular infarction has been attributed to a low output type of left ventricular failure (Zaus and Kearns, 1952), but this view cannot be sustained by experimental results. Several workers have shown that massive infarction of the right ventricle produced in dogs, fails to cause heart failure, except possibly after a latent period of several months (Starr et al., 1943; Bakos, 1950; and Donald and Essex, 1954). In dogs the dominant artery on the posterior cardiac wall is the left circumflex; hence occlusion of the right coronary artery will not impair the nutrition of either the posterior inter-ventricular septum or the adjacent portion of the left ventricular wall. In man, on the other hand, it is the extension of the infarct into these areas that probably accounts for the presence of circulatory failure in cases of right ventricular infarction. In addition, the dogs were anæsthetized during these operations and consequently suffered no pain, in the early stages at any rate, whereas the severe pain that was experienced in the human cases probably resulted in some vaso-vagal effect (Wright, 1952).

\section{ConClusions}

Extensive infarction of the right ventricle is usually a direct result of an occlusion of the right coronary artery. Earlier occlusive lesions occurring in the anterior descending branch of the left coronary artery probably play a considerable rôle in the pathogenesis of this type of infarct.

Since the right coronary artery is usually the dominant vessel on the posterior cardiac wall, there is frequently an extension of the infarct to the posterior interventricular septum and adjoining portion of the left ventricle. It is suggested that it is this extension of the lesion rather than the involvement of the right ventricle itself that contributes to the high incidence of circulatory failure in these cases. Extension of the infarct to the right atrium is also relatively common.

There is evidence suggesting that pulmonary hypertension plays an ætiological rôle in right ventricular infarction.

When the thin-walled right ventricle becomes infarcted, the lesion is particularly liable to become transmural; hence rupture, pericarditis, mural thrombosis, and pulmonary embolism are frequent attendant lesions.

The histological features of right ventricular infarction closely resemble those of left ventricular infarction.

Without the assistance of an electrocardiogram including right præcordial leads, there is little chance of achieving a precise clinical diagnosis. The prognosis in patients with right ventricular infarction tends to be poor and the increased risk of pulmonary embolism makes the use of anticoagulant therapy imperative, although the tendency for hepatic insufficiency to develop necessitates great care in its use.

Several physiological factors acting through the inter-coronary collateral circulation are enumerated as being responsible for the relative immunity of the right ventricle to infarction.

Thanks are due to Prof. J. H. Biggart for his help and criticism in the preparation of this paper. I am also grateful to Dr. J. F. Pantridge for his comments on the electrocardiographic aspects, and to Dr. D. A. D. Montgomery for supplying me with the clinical details of one of his cases. I am indebted to Mr. David Mehaffey for the photographs and to Mrs. Dundas for secretarial assistance. 


\section{REFERENCES}

Bakos, A. C. P. (1950). Circulation, 1, 724.

Bean, W. B. (1938/39). Ann. intern. Med., 12, 71.

Blumgart, H. L., Schlesinger, M. J., and Davis, D. (1940). Amer. Heart. J., 19, 1.

Case 34442. [Mass. Gen. Hosp. (1948)]. New Eng. J. Med., 239, 683.

Cushing, E. H., Feil, H. S., Stanton, E. J., and Wartman, W. B. (1942). Brit. Heart J., 4, 17.

Donald, D. E., and Essex, H. E. (1954). Amer. J. Physiol., 176, 431.

Eckstein, R. W., Roberts, J. T., Gregg, D. E., and Wearn, J. T. (1941). Amer. J. Physiol., $132,648$.

Egeli, E. S. (1956). Sem. Hôp. Paris, 32, 1-7.

Evans, W. (1956). Cardiology. (Butterworth), London.

Feil, H. S., Cushing, E. H., and Hardesty, J. T. (1938). Amer. Heart J., 15, 721.

Gould, S. E. (1953). Pathology of the Heart. C. C. Thomas (Springfield).

Gregg, D. E. (1950). Coronary Circulation in Health and Disease. H. Kimpton, London.

Gross, L. (1921). The Blood-supply to the Heart. P. B. Hoeber, New York.

Johnston, F. D. (1956). Personal communication. Univ. Michigan.

Levy, L., and Hyman, A. L. (1950). Amer. Heart J., 39, 243.

Mallory, G. K., White, P. D., and Salcedo-Salgar, J. (1939). Amer. Heart J., 18, 647.

McDonald, G. E., and Bentley, W. B. A. (1951). New Eng. J. Med., 244, 743.

Palmer, J. H. (1937). Lancet, 1, 741.

Prinzmetal, M., Kayland, S., Margoles, C., Toragerman, L. J. (1942). J. Mt. Sinai Hosp., 8, 933.

, Bergman, H. C., Kruger, H. E., Schwartz, L. L., Simkin, B., and Sobin, S. S. (1948). Amer. Heart J., $35,689$.

Roberts, J. T., and Loube, S. D. (1947). Amer. Heart J., 34, 188.

Sanders, A. O. (1930/31). Amer. Heart J., 6, 820.

Schlesinger, M. J., and Zoll, P. M. (1941). Arch. Path., 32, 178.

Sprague, H. B., and Orgain, E. S. (1935). New Eng. J. Med., 212, 903.

Starr, I., Jeffries, W. A., and Meade, R. H. (1943). Amer. Heart J., 26, 291.

Wade, W. G. Thesis: Studies in Pathogenesis of Myocardial Infarction of the Right Ventricle (1957).

Wartman, W. B., and Hellerstein, H. K. (1948). Ann. intern Med., 28, 41.

-, and Souders, J. C. (1950). Arch. Path., 50, 329.

Wearn, J. T. (1928). J. exp. Med., 47, 273 and 293.

, Mettier, S. R., Klumpp, T. G., and Zschiesche, L. J. (1933). Amer. Heart J., 9, 143.

Weinberg, H. B., and Katz, L. N. (1941). Amer. Heart J., 21, 699.

White, P. D. (1947). Heart Disease. 3rd ed. MacMillan (New York).

Wiggers, C. J. (1954). Circulation Res., $2,271$.

Wood, P. H. (1956). Diseases of the Heart and Circulation. 2nd ed. Eyre and Spottiswoode, London.

Wright, S. (1952). Applied Physiology. 9th ed. Oxford Univ. Press, London.

Zaus, E. A., and Kearns, W. M. (1952). Circulation, 6, 593. 